\title{
DETEKSI DIAMETER KANKER PAYUDARA MENGGUNAKAN SEGMENTASI CITRA BERDASARKAN METODE OTSU THRESHOLDING
}

\author{
Tessa Putri Mallini ${ }^{1}$, Erfian Junianto ${ }^{2}$, Yudi Ramdhani ${ }^{3}$ \\ 1 Universitas Adhirajasa Reswara Sanjaya \\ email: tessamallini@gmail.com \\ 2Universitas Adhirajasa Reswara Sanjaya \\ email: erfian.ejn@ars.ac.id \\ ${ }^{3}$ Universitas Adhirajasa Reswara Sanjaya \\ email: yudi@ars.ac.id
}

\begin{abstract}
Abstrak
Kanker merupakan salah satu penyebab kematian utama di dunia. Pada tahun 2012, sekitar 8.2 juta kematian yang disebabkan oleh kanker, salah satunya yaitu kanker payudara. Kanker payudara didiagnosa melalui pemeriksaan rutin atau ketika pasien menyadari gejala-gejala tertentu, tetapi pemeriksaan fisik saja tidak cukup sehingga diterapkan salah satu metode yaitu metode segmentasi citra. Secara umum tahapan dalam processing ini adalah mengambil citra asli, lalu citra asli dilakukan proses Enhancement atau perbaikan citra dengan Intensity Adjustment. Selanjutnya dilakukan segmentasi menggunakan metode Otsu Thresholding, kemudian dilakukan perhitungan diameter kanker payudara dalam satuan piksel dan diubah menjadi milimeter. Hasil penelitian deteksi diameter kanker payudara terhadap 50 citra, diperoleh hasil bahwa metode pengolahan citra yang diusulkan dapat mendeteksi diameter dan berhasil mengidentifikasi citra, dengan sampel image mammogram 26 cancer, 13 benign, dan 11 normal. Dengan persentasi tingkat kebenarannya sebesar $72 \%$ dan kesalahannya $28 \%$.
\end{abstract}

Kata Kunci: Enhancement, Intensity Adjustment, Kanker Payudara, Otsu Thresholding, Segmentasi

\begin{abstract}
Cancer is one of the leaading causes of death in the world. In 2012, about 8,2 million, deaths are caused by cancer. One of them is breasth cancer. Breasth cancer is diagnosed through a routine checks or when the pakent is aware of certain symproms but only physical checks is not enough so applied one of methot, that is image segmentation method. Generaliy, step inthis processing is to take original image, then the original image was done Enhancement process or image improvement with Intensity Adjustment. Next, segmentation was done by using Otsu Thresholding method, then perfommed the calculation of breast cencer diameter in pixel unit and converted into milimeter. The result of the detection breast cancer diameter on 50 images obtained the result that the proposed image processing method can detect the diameter and successfully identify the image, with samples of 26 cancer, 13 benign, and 11 normal mamogram image. With a percntage of truth level of $72 \%$ and error $28 \%$.
\end{abstract}

Keywords: Enhancement, Intensity Adjustment, Breast Cance, Otsu Thresholding, Segmentation 


\section{Pendahuluan}

Kanker menjadi salah satu penyebab utama kematian di seluruh belahan dunia. Tahun 2012, kematian yang disebabkan oleh kanker berjumlah sekitar 8.2 juta, diantaranya yaitu kanker payudara. Kanker payudara adalah tumor ganas yang terbentuk dari sel-sel payudara yang tumbuh dan berkembang tanpa terkendali sehingga dapat menyebar diantara jaringan atau organ di dekat payudara atau bagian tubuh lainnya (Pusat Data Dan Informasia Kementrian Kesehatan RI, 2016).

Pada dasarnya, kanker payudara didiagnosa melalui suatu pemeriksaan rutin atau ketika pasien menyadari gejala-gejala tertentu, tetapi melakukan pemeriksaan dari sisi fisik saja masih belum cukup untuk mengkonfirmasi diagnosa kanker payudara sehingga dilakukan berbagai prosedur pemeriksaan seperti mamografi, biopsy, serta menggunakan sinar- $X$ yang memberikan gambaran tentang jaringan lunak pada payudara. Pemeriksaan ini berguna untuk mendeteksi masalah atau penyakit yang ada pada payudara. Setelah dilakukan mamografi terhadap pasien, hasil mamografi tersebut harus di lakukan pengujian laboraturium untuk mendeteksi pengenalan area kanker. Dalam bidang kedokteran sering mengalami kesulitan dalam mengamati citra Mamografi, karena hasil citra mempunyai drajat keabuan sehingga sulit untuk melihat jenis area bagian kanker (Handayani \& Septa, 2014).

Untuk membantu permasalahan tersebut maka perlu diterapan pengolahan citra, agar citra mikroskopis dari kanker payudara dapat di analisis. Salah satu metode yang digunakan yaitu metode segmentasi citra. Sebuah proses agar objek dan background dapat dipisahkan disebut segmentasi citra. Dari proses tersebut masing-masing objek dapat digunakan Kembali sebagai masukan bagi proses yang lainnya (Arifin, 2016).

Penelitian ini menggunakan segmentasi obyek pada sebuah citra digital yaitu metode atau teknik otsu thresholding. Penelitian ini dapat dibagi menjadi lima proses, masing-masing adalah masukan data citra, pre-processing, cleaning, segmentasi, dan penghitungan akurasi. Penelitian ini menggunakan database dari Weizmann Segmentation kurang lebih 30 citra digital format RGB. Pengujian tersebut mendapat hasil akurasi sebesar 93,33\% (Syafi'i, Wahyuningrum, \& Muntasa, 2015).
Dari hasil penelitian sebelumya maka penelitian ini akan membahas mengenai cara menghitung kalkulasi diameter kanker payudara. Tahapan umum untuk melakukan kalkulasi diameter kanker payudara adalah dengan mengambil citra asli, kemudian citra asli tersebut diberikan proses Enhancement atau perbaikan citra, perbaikan kualitas citra dapat dilakukan dengan metode Intensity Adjustment agar citra yang di masukan mempunyai kualitas yang lebih baik. Dari hasil perbaikan kualitas citra dilakukan proses segmentasi yaitu menggunakan Otsu Thresholding methode. Setelah hasil segmentasi diperoleh, dilakukan perhitungan luas area dan diameter kanker payudara dalam satuan piksel. Konfersi satuan diameter yang semula piksel diubah menjadi milimeter. Hasil segmentasi merupakan tahap alhir yang menentukan kalkulasi diameter kanker payudara.

\section{Metode Penelitian}

\subsection{Preprocessing}

Operasi pengolahan citra atau Image enhancement merupakan teknik untuk memberikan peningkatan kualitas citra. Operasi ini memiliki tujuan untuk menonjolkan atau memperbaiki ciri tertentu dari suatu citra. Sehingga kualitas citra menjadi lebih baik. Pengolahan citra ini menggunakan teknik grayscale.

Grayscale adalah citra digital yang terdapat warna keabuan, warna hitam, dan warna putih (Munir, 2004). Tingka keabuaan pada teknik ini merupakan kandungan warna abu dengan berbagai tingkatan, mulai dari warna hitam hingga mendekati warna putih. Citra grayscale mempunyai kedalaman warna 8 bit (256 komposisi warna keabuan). Selain itu, operasi titik, operasi spasial, dan operasi transformasi dapat digunakan untuk melakukan operasi pengolahan citra (Munir, 2004).

Teknik yang dapat dicoba berdasarkan cakupan operasinya, untuk melakukan image processing adalah operasi titik. Operasi ini adalah teknik yang dilakukan untuk melakukan perubahan pada histogram dari citra masukan agar sesuai dengan karakter yang diinginkan. Histogram merupakan grafik yang memberikan gambaran penyebaran terhadap nilai intensitas piksel terhadap suatu citra atau bagian-bagian tertentu dari citra, seperti pada gambar 1. Secara matematis, operasi titik dinyatakan sebagai :

$$
f_{B}(x, y)=0_{\text {titik }}\left\{f_{A}(x, y)\right\}
$$


Dimana :

$\mathrm{f}_{\mathrm{A}}=$ citra masukan

$\mathrm{f}_{\mathrm{B}}=$ citra keluaran

$0_{\text {titik }}=$ Operasi linier atau non linier

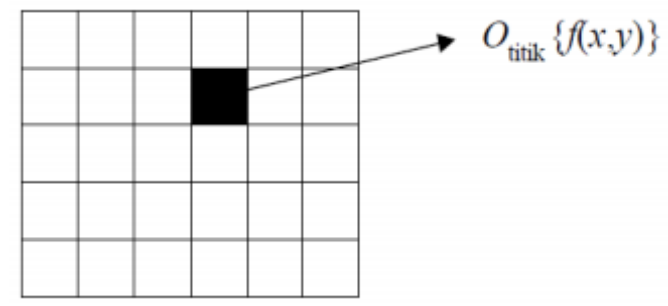

Gambar 1. Operasi Titik

Sumber : (Munir, 2004)

Operasi linier merupakan operasi yang dinyatakan secara matematis. Sedangkan persamaan non-linier adalah kebalikannya. Berikut teknik operasi titik yang digunakan dalam pengolahan citra yaitu, intensity adjustment, histogram equalization, dan thresholding.

a. Intensity Adjustment

Melakukan perubahan pada nilai intensitas dari suatu histogram yang lama dengan transformasi persamaan linear menjadi nilai intensitas terhadap histogram yang baru. Suatu konstanta dapat ditentukan dengan histogram yang merupakan faktor dari penyesuaian terhadap operasi titik pada intensity adjustment. Dengan model matematis, notasi intensity adjustment dapat dinyatakan sebagai berikut:

$$
f(x, y)^{\prime}=f(x, y)+b
$$

$f(x, y)^{\prime}=$ citra setelah penyesuaian

$f(x, y)=$ citra sebelum dilakukan penyesuaian,

$\mathrm{b}=$ suatu konstanta yang menjadi faktor untuk penyesuaian. Jika $b$ dinyatakan positif, gambar menjadi lebih cerah, sebaliknya jika $b$ dinyatakan negatif gambar menjadi kurang cerah (Munir, 2004).

Penyesuaian proses dapat dilakukan dengan cara melakukan penambahan atau pengurangan nilai pada setiap piksel terhadap suatu konstanta. Jika nilai piksel setelah dilakukan penyesuaian menjadi lebih tinggi dari nilai maksimum intensitas yang memungkinkan untuk sebuah citra grayscale, maka nilai piksel akan dijadikan 255. Hal tersebut dikarenakan nilai maksimum intensitas adalah 255. Demikian juga sebaliknya, jika terdapat nilai piksel hasil penyesuaian lebih menjadi kecil dari 0 (nol), maka nilai piksel tersebut dijadikan 0

(Putra D. , 2010).

b. Histogram Equalization

Histogram equalization memiliki tujuan untuk menghasilkan sebuah citra keluaran yang mempunyai nilai histogram relatif sama.

c. Thresholding

Metode Thresholding adalah proses pemisahan piksel yang didasarkan pada derajat keabuan yang dimilikinya. Piksel yang mempunyai derajat keabuan lebih kecil dari nilai batas yang ditentukan akan diberikan nilai 0 , sedangkan piksel yang memiliki derajat keabuan yang lebih besar dari batas akan diubah menjadi bernilai 1 .

\subsection{Otsu Thresholding}

Teknik/metode otsu merupakan cara untuk membagi histogram dari citra gray level ke dalam dua daerah yang berbeda secara otomatis, tanpa bantuan user untuk memasukkan nilai ambang. Metode Otsu memiliki pendekantan dengan cara melakukan analisis diskriminan, yaitu menentukan nilai suatu variabel yang dapat membedakan antara dua atau lebih kelompok yang muncul secara alami. Analisis Diskriminan memaksimumkan variabel tersebut agar dapat melakukan pembagian objek latardepan (foreground) dan objek latar belakang (background). Formulasi metode otsu sebagai berikut :

Nilai ambang yang dicari dari suatu citra gray level dinyatakan dengan variable $\mathrm{k}$. Nilai $k$ berkisar antara 1 sampai dengan $L$, dengan nilai L adalah 255 (Putra D. , 2010). Probabilitas pada setiap pixel pada level ke i dapat dinyatakan:

Dengan :

$$
p_{i}=n_{i} / N
$$

ni menyatakan pada jumlah pixe/ pada level ke I

$\mathrm{N}$ menyatakan total jumlah pixe/ pada suatu citra.

Otsu Thresholding adalah metode yang membantu melakukan segmentasi pada citra digital dengan mencari segmentasi threshold dan menggunakan analisa histogram. Proses threshold merupakan proses untuk melakukan perubahan citra grayscale multi value, menjadi citra biner bivalue (dua nilai saja). Proses tersebut dapat dituliskan menggunakan notasi matematis sebagai berikut (Aristyagama, 2016). 


$$
g(x, y)\left\{\begin{array}{l}
1 \text { if } f(x, y) \geq T \\
0 \text { if } f(x, y)<T
\end{array}\right.
$$

Dimana $\mathrm{g}(\mathrm{x}, \mathrm{y})$ merupakan nilai piksel hasil threshold pada baris $\mathrm{x}$ dan kolom $\mathrm{y}$, sedangkan $\mathrm{T}$ merupakan nilai threshold sebagai batas dari nilai keabuan untuk mengkonversi nilai piksel $f(x, y)$ menjadi nilai piksel $\mathrm{g}(\mathrm{x}, \mathrm{y})$.

Otsu Thresholding disarankan untuk menentukan threshod yang meminimalkan bobot variansi within-class. Hal tersebut sama dengan memaksimalkan variansi beetwen-class. Otsu Thresholding bekerja pada citra dengan menggunakan model warna grayscale (Aristyagama, 2016).

Berikut gambar 2 yang menggambarkan hasil dari proses Otsu Thresholding.

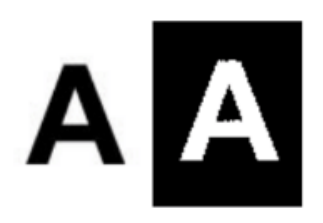

Gambar 2. Citra asli (Kiri) dan citra hasil Otsu Thresholding (Kanan)

Sumber : (Aristyagama, 2016).

\subsection{Segmentasi}

Segmentasi citra merupakan sebuah proses untuk melakukan pemisahan terhadap sebuah objek dari background, sehingga objek dapat diproses untuk keperluan lainnya.

Suatu segmentasi citra berdasar pada salah satu property nilai intensitas, yaitu diskontinuitas dan kemiripan. Pendekatan yang menggunakan pemecahan/pemilahan citra menggunakan perubahan yang kasar pada suatu intensitas disebut diskontinuitas, misalnya tepi dalam sebuah citra. Sedangkan, penggunaan model kemiripan yaitu pemecahan citra ke pada suatu region yang sama berdasarkan kriteria-kriteria yang telah didefinisikan, yaitu region growing, thresholding, merging, dan region splitting (Prasetyo, 2011).

a. Deteksi Diskontinuitas

Langkah-langkah yang paling banyak digunakan untuk mencari titik diskontinuitas ialah menjalankan mask kepada seluruh citra. Langkah-langkah dari komputasinya merupakan akumulasi dari hasil perkalian koefisien terhadap nilai dari gray level yang mengisi bagian region yang telah ditempati oleh suatu mask.

$$
\begin{aligned}
& R=w 1 z 1+w 2 z 2+\cdots+w 9 z 9 \\
& =\sum_{i=1}^{9} W i Z i
\end{aligned}
$$

Hasil dari masking sembarang titik dalam suatu citra adalah dimana $\mathrm{Zi}$ adalah gray level pixel yang diasosiasikan dengan koefisien mask Wi, seperti pada gambar 3.

\begin{tabular}{|c|c|c|}
\hline W1 & W2 & w3 \\
\hline W4 & W5 & W6 \\
\hline W7 & w8 & w9 \\
\hline
\end{tabular}

a. Mask Umum

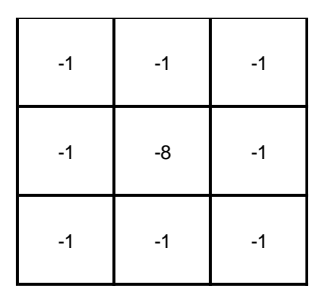

b. Mask Laplacian
Gambar 3. Mask 3×3

Sumber : (Prasetyo, 2011)

b. Deteksi Titik

Titik dideteksi pada sebuah lokasi dimana mask dipusatkan jika:

$|R| \geq T$

$\mathrm{T}=$ threshold non-negatif dan $\mathrm{R}$ diberikan persamaan masking. Pada umumnya rumus ini dipakai untuk melakukan pengukuran perbedaan terhadap bobot diantara titik pusat dan titik tetangga dari mask. Isolating point merupakan suatu titik di mana titik gray level-nya berbeda secara signifikan dari background-nya. Penempatan pada daerah homogenous akan berbeda dari sekitarnya, maka dari itu dapat dengan mudah dideteksi (Prasetyo, 2011).

c. Deteksi Garis

Apabila notasi R1, R2, R3, dan R4 merupakan pernyataan hasil mask kiri ke kanan, dan apabila nilai $\mathrm{R}$ diberikan dari persamaan dan apabila empat mask dijalankan masing-maing terhadap suatu citra, untuk suatu titik tertentu dalam sebuah citra, $|R i|>|R j|$ untuk semua $j \neq i$, titik tersebut dapat dinyatakan lebih berasosiasi dengan garis dalam arah mask i.

Alternatif lainnya, deteksi garis dapat dilakukan dari arah tertentu. Pada kasus ini, mask dapat berasosiasi dengan arah dan output dari threshold (Prasetyo, 2011). Berikut gambar 4, yang menggambarkan kasus tersebut. 


\begin{tabular}{|l|l|l|}
\hline-1 & -1 & -1 \\
\hline 2 & 2 & 2 \\
\hline-1 & -1 & -1 \\
\hline
\end{tabular}

\begin{tabular}{|l|l|l|}
\hline 2 & -1 & -1 \\
\hline-1 & 2 & -1 \\
\hline-1 & -1 & 2 \\
\hline
\end{tabular}

a. Horizontal
\begin{tabular}{|c|c|c|}
\hline-1 & 2 & -1 \\
\hline-1 & 2 & -1 \\
\hline-1 & 2 & -1 \\
\hline
\end{tabular}

a. Vertikal

b. $+45^{\circ}$
\begin{tabular}{|c|c|c|}
\hline-1 & -1 & 2 \\
\hline-1 & 2 & -1 \\
\hline 2 & -1 & -1 \\
\hline
\end{tabular}

b. $-45^{\circ}$

Gambar 4. Mask untuk deteksi garis

Sumber : (Prasetyo, 2011)

d. Deteksi Tepi

Merupakan pendekatan dasar untuk melakukan deteksi diskontinuitas pada intensitas, layaknya diskontinuitas yang dapat dideteksi oleh turunan pertama dan turunan kedua. Pilihan pertama pada turunan pengolahan citra ialah Gradien. Fungsi dari 2-D $(x, y)$ dinyatakan sebagai vektor. Sedangkan turunan kedua dalam pengolahan citra dapat dihitung dengan menggunakan model Laplacian, sehingga notasi Laplacian 2-D $(x, y)$ dapat dibentuk oleh turunan kedua (Prasetyo, 2011).

$$
\begin{aligned}
& \nabla \boldsymbol{f}=\left[\frac{G x}{G y}\right]=\left[\begin{array}{l}
\frac{\partial f}{\partial x} \\
\frac{\partial f}{\partial y}
\end{array}\right] \\
& \nabla 2(x, y)=\frac{\partial 2 f(x, y)}{\partial x 2}+\frac{\partial 2 f(x, y)}{\partial y 2}
\end{aligned}
$$

Laplacian jarang berdiri sendiri tanpa melibatkan deteksi tepi, sebagai turunan kedua, model Laplacian tidak terlalu sensitif terhadap suatu noise. Deteksi tepi membentuk tepi double dan tidak dapat mengetahui arah tepi, sedangkan model Laplacian dapat menjadi pelengkap yang dengan kinerja yang baik. Dasar pengetahuan deteksi tepi ialah untuk megnetahui tempat pada sebuah citra, di mana intensitas tersebut berubah dengan cepat. Kriteria umum yang digunakan sebagai berikut:

a. Melakukan pencarian tempat di mana pada turunan pertama dari suatu intensitas lebih besar jaraknya daripada threshold yang ditetapkan.

b. Melakukan pencarian tempat di mana turunan kedua dari suatu intensitas memiliki zero crossing.

\section{Hasil dan Pembahasan}

\subsection{Rancangan Program}

a. Rancangan Menu Halaman Depan

Merupakan halaman depan dari aplikasi deteksi diameter kanker payudara. Di dalam halaman ini terdapat menu utama, menu bantuan dan keluar. Berikut gambar 5 , yang merupakan rancangan halaman menu utama pada aplikasi matlab.

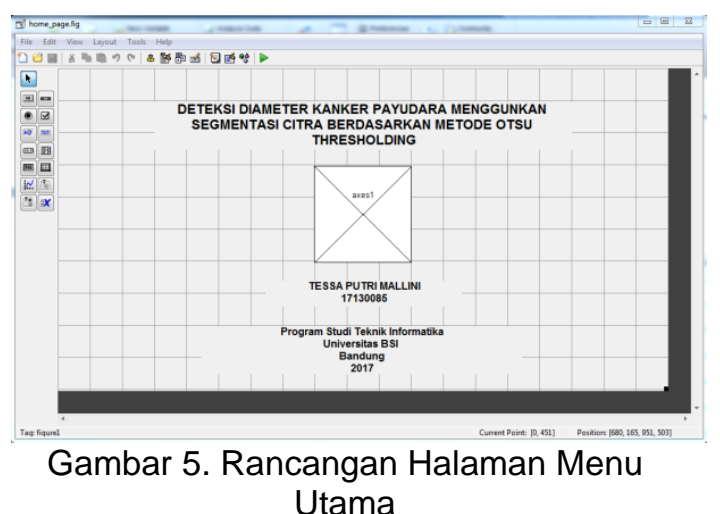

b. Rancangan Menu Halaman Utama Kalulasi Diameter Kanker Payudara

Halaman ini merupakan halaman untuk menentukan kalkulasi diameter kanker. Halaman ini terdapat bagian utama yaitu 4 buah akses untuk menampilkan citra asli, citra hasil pre-prosesing, citra hasil Thresholding dengan metode Otsu Thresholding, dan citra hasil segmentasi, 6 buah pusbutton yaitu buka citra, preprosesing, Thresholding, hasil segmentasi, diameter, dan reset, seperti pada gambar 6 .

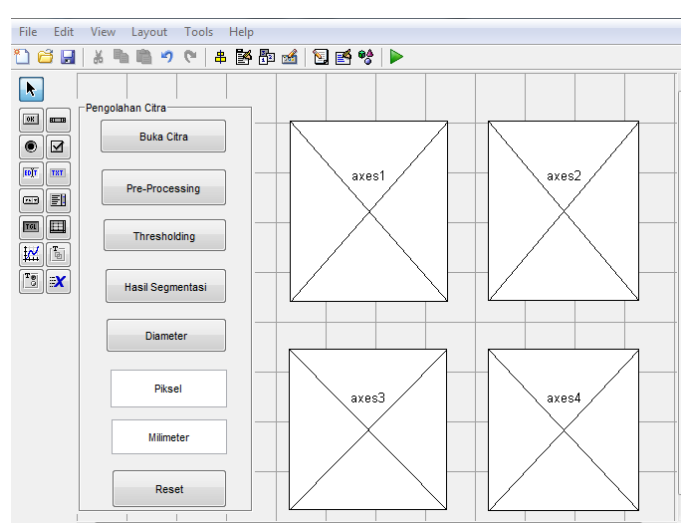

Gambar 6. Rancangan Halaman Kalkulasi Diameter Kanker Payudara 
c. Rancangan Halaman Bantuan Merupakan petunjuk

cara menggunakan program deteksi diameter kanke. Halaman ini menjelaskan semua menu yang terdapat pada program, seperti terlihat pada gambar 7 .

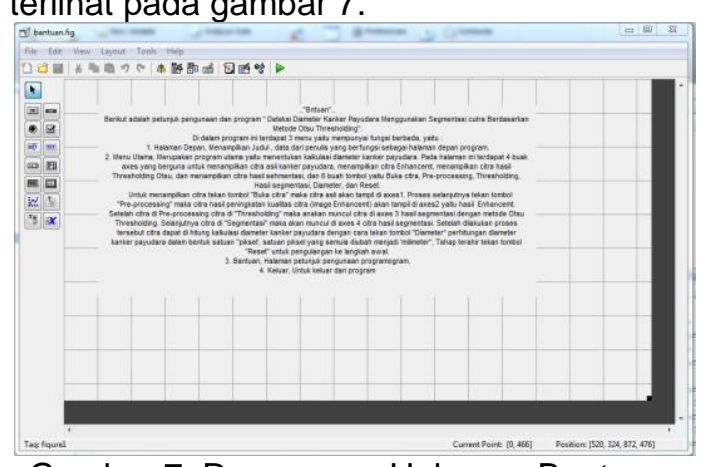

Gambar 7. Rancangan Halaman Bantuan Aplikasi

\subsection{Perancangan UML}

a. Use Case Diagram

Gambar 8, ditunjukan Use Case Diagram yang mengambarkan peran User yang dapat memilih salah satu menu yang terdapat pada aplikasi. Diantaranya yaitu ada menu utama untuk proses penentuan deteksi diameter kanker payudara, Halaman depan yang berisi menganai profil penulis aplikasi program, dan Halaman bantuan yang berisi mengenai petunjuk pengunaan program.

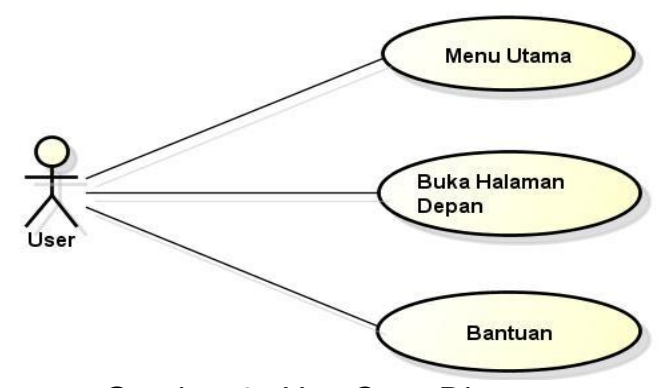

Gambar 8. Use Case Diagram

b. Activity Diagram Menu Halaman Depan Gambar 9 menunjukkan kegiatan dari menu halaman depan. Proses ini merupakan rangkaian awal untuk melakukan proses berikutnya.

c. Activity Diagram Menu Utama

Aktifitas menu utama merupakan aktifitas untuk melalukan pengolahan citra dan mendapatkan hasil dari pengolahan tersebut, alurnya seperti ditunjukkan pada gambar 10 . d. Activity Diagram Menu Bantuan Menu bantuan merupakan menu untuk melihat bagaimana aplikasi digunakan, dan juga informasi lainnya. Alur aktifitas tersebut terlihat pada gambar 11 .

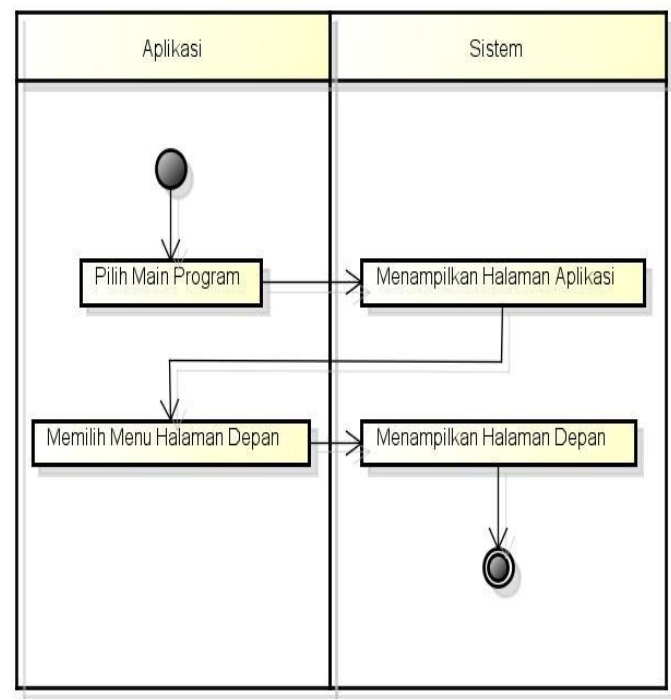

Gambar 9. Diagram Aktifitas Menu Halaman Depan

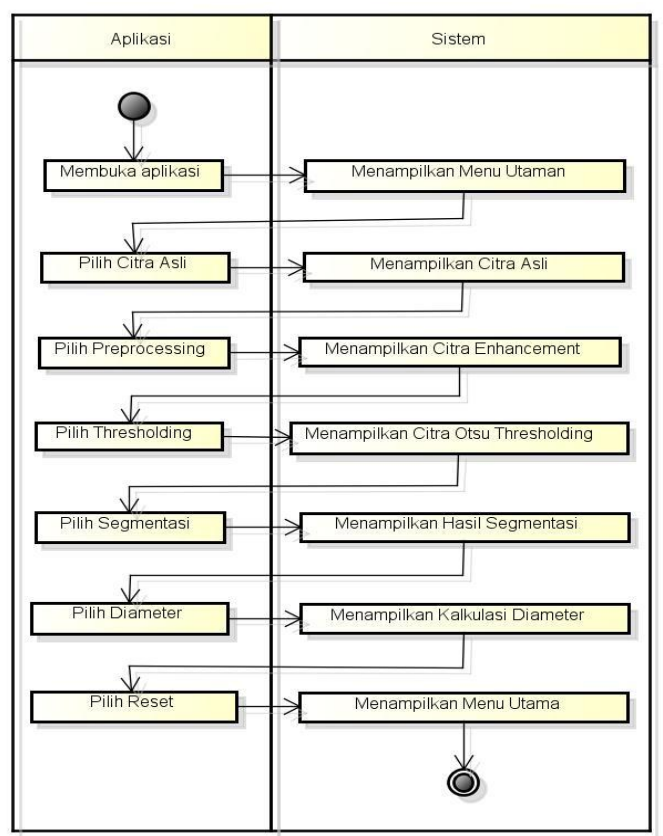

Gambar 10. Diagram Aktifitas Menu Utama 


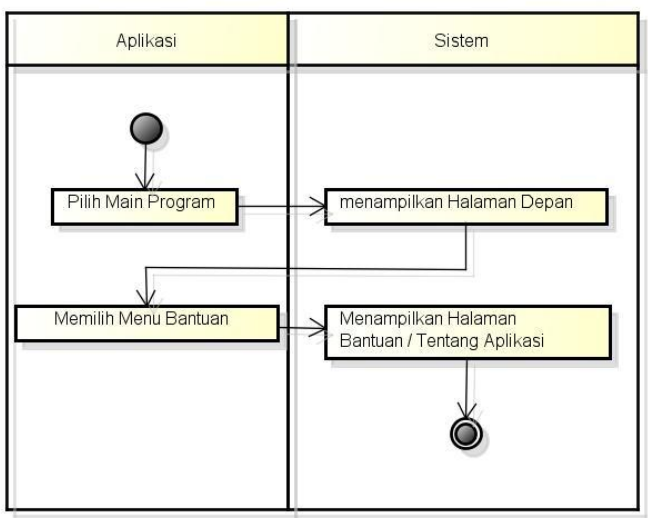

Gambar 11. Diagram Aktifitas Menu Bantuan

\subsection{Flowchart}

Citra masukan pada proses deteksi diameter kanker payudara adalah citra hasil segmentasi dengan metode Otsu Thresholding pada tahap sebelumnya. Langkah awal untuk melakukan deteksi diameter kanker payudara adalah dengan mempreprocessing citra dengan intensity Adjustment. Metode Otsu Thresholding digunakan untuk perhitungan kalkulasi diameter kanker payudara. Proses yang dilakukan terlihat pada gambar 12 .

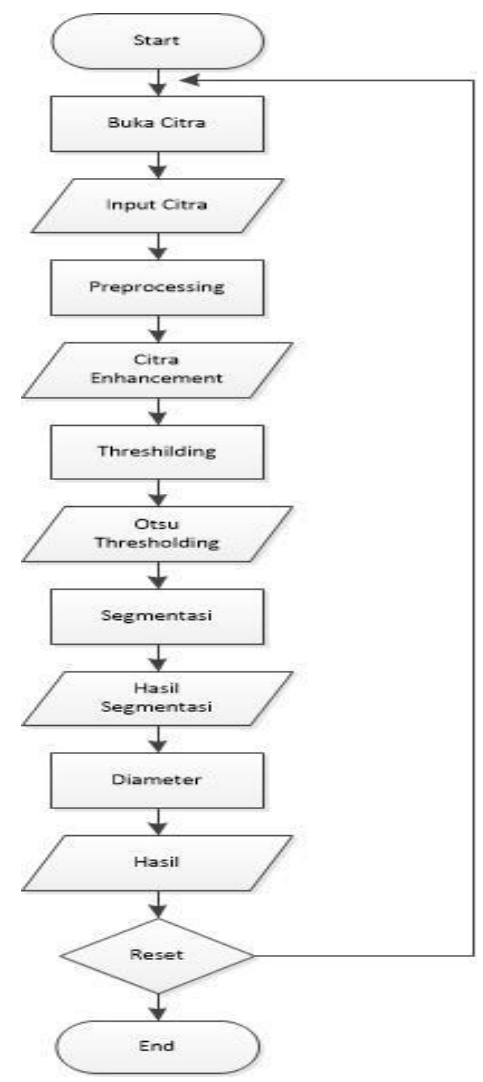

Gambar 12. Flowchart Deteksi Diameter Kanker Payudara

\subsection{Implementasi}

a. Input Citra Asli

Pada menu utama pilih menu buka citra, kemudian pilih image yang akan diinput sehingga akan menampilkan citra asli. Seperti terlihat pada gambar 13 .

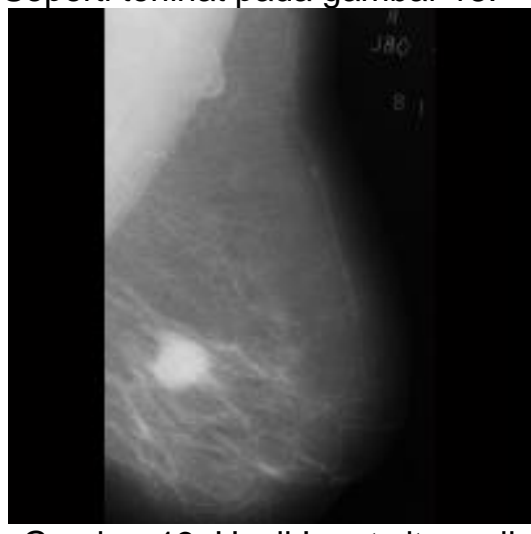

Gambar 13. Hasil Input citra asli

b. Perbaikan Kualitas Citra

Setelah menampilkan citra asli, langkah selanjutnya pilih pre-processing agar citra memiliki kualitas citra yang lebih baik. Hasilnya seperti terdapat pada gambar 14 .

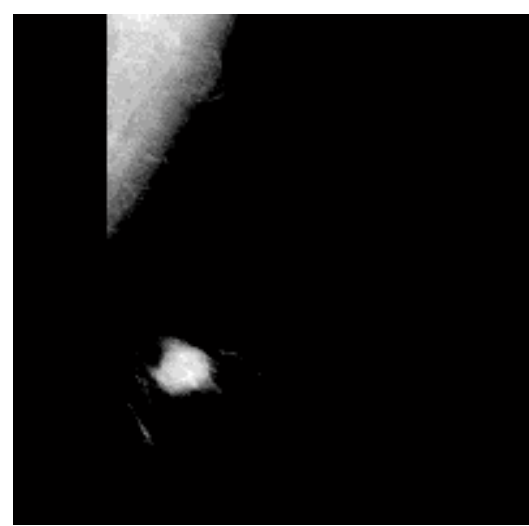

Gambar 14. Citra hasil preprocessing

c. Segmentasi dengan Metode Otsu Thresholding

Setelah citra di perbaiki kualitas citranya, pilih Thresholding yang bertujuan untuk memisahkan bagian sel kanker dengan payudara tanpa membutuhkan user untuk memasukkan nilai ambang. Seperti terlihat pada gambar 15 . 


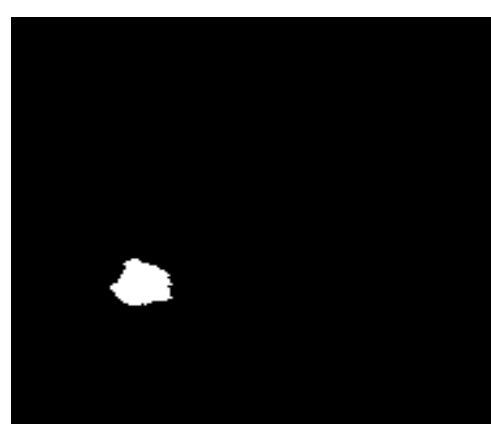

Gambar 15. Citra hasil Thresholding dengan metode Otsu

d. Segmentasi

Dari hasil segmentasi citra yang telah melalui proses kontruksi morfologi deteksi. Langkah berikutya citra yang telah memiliki tepi dan sudah dideteksi dengan utuh, sehingga dapat dilanjutkan ke tahap kalkulasi diameter kanker payudara. Hasil proses tersebut terllihat pada gambar 16

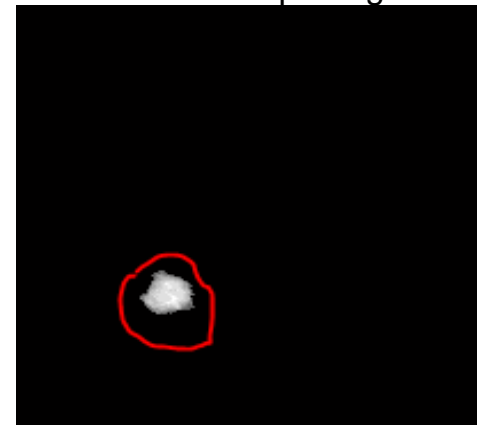

Gambar 16. Citra hasil segmentasi

e. Kalkulasi Diameter Kanker Payudara

Hasil dari segmentasi dapat dihitung kalkulasi diameter kanker payudara dengan menggunakan rumus $\mathrm{D}=$ sqrt $(4 \times$ Luas $/ \mathrm{pi})$, karena bentuk dari selkanker tidak selalu bulat. Hasil angka dari diameter citra masih berupa pixel. Oleh karena itu, seperti pada gambar 17, angka diameter citra dikonversikan kembali kedalam satuan yang dipakai dalam karakteristik diteksi diameter kanker yaitu milimeter.

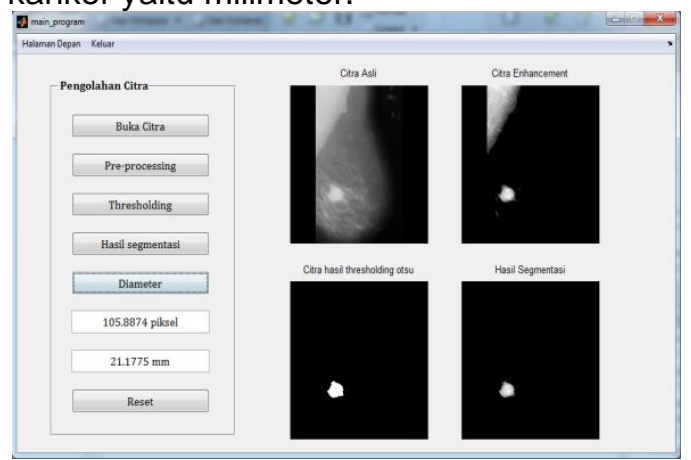

Gambar 17. Citra hasil kalkulasi diameter kanker payudara f. Tombol Reset

Menu ini berfungsi untuk menghapus semua pekerjaan yang telah dikerjakan sesuai dengan kondisi pertama aplikasi dijalankan semua tombol fungsi dan perangkat yang ada pada form ini tidak bisa dijalankan, lihat gambar 18

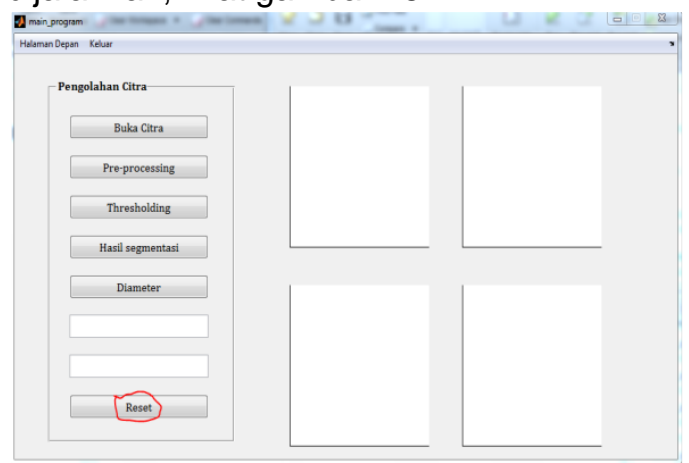

Gambar 18. Tombol reset

\section{Kesimpulan}

Dari hasil yang telah dipaparkan, dapat disimpulkan sebagai berikut:

a. Perbaikan kualitas citra merupakan proses yang cukup penting. Karena citra yang dihasilkan dari mammography masih memiliki kontras yang rendah. Dalam proses perbaikan kualitas citra dapat menggunakan metode intensity Adjustment agar citra memiliki kualitas yang lebih baik.

b. Analisis segmentasi citra adalah titik awal agar dapat menentukan ciri objek di dalam sebuah citra. Metode Otsu Thresholding adalah yang terbaik, karena dapat melakukan deteksi terhadap tepi objek kanker pada citra.

c. Untuk mendapatkan hasil kalkulasi diameter kanker payudara dapat menggunakan metode Otsu Thresholding. Hasil angka dari diameter citra masih berupa pixel. Oleh karena itu, angka diameter citra dikonversikan kembali kedalam satuan yang dipakai dalam karakteristik diteksi diameter kanker yaitu milimeter.

Hasil deteksi diameter kanker payudara terhadap 50 citra, didapatkan hasil bahwa metode yang diusulkan dapat mendeteksi diameter dan berhasil mengidentifikasi citra tersebut, dengan sampel image mammogram 26 cancer, 13 benign, dan 11 normal. Dengan persentasi tingkat kebenarannya sebesar $72 \%$ dan kesalahannya $28 \%$. 
Dari kesimpulan tersebut dapat diberikan saran sebagai berikut:

a. Dalam penelitian ini masih menggunakan citra yang didapat dari internet. Untuk penelitian selanjutnya disarankan untuk menggunakan citra yang didapat dari rumah sakit, sehingga kualitas dan hasil segmentasi lebih akurat.

b. Penelitian ini hanya membahas sampai kakulasi diameter, untuk penelitian selanjutnya dapat ditambahkan penentuan dan klasifikasi penentuan stadium Kanker.

c. Penelitian ini menggunakan metode Otsu Thresholding, untuk metode selanjutnya disarankan untuk menggunakan Algoritma lain dalam mensegmentasi citra kanker payudara, sehingga bisa dilakukan perbandingan Algoritma mana yang memberikan hasil segmentasi yang lebih baik.

\section{Referensi}

Arifin, T. (2016). Analisa Perbandingan Metode Segmentasi Citra Pada Citra Mammogram , 156-163.

Aristyagama, Y. H. (2016). Pengenalan Karakter Sintaktik Mengguakan Algoritma Otsu dan Zhang-suen. Dipetik Juli 2017, 12, dari hhtp://www.researcehgate.net

Handayani, L., \& Septa, I. I. (2014). Segmentasi Mamografi Kanker Payudara Dengan Algoritma Expectation Maximazation Segmentation (EMSEGMENTATION) , 251-258. Manajemen Modern dan Kesehatan

Munir, R. (2004). Pengolahan Citra Digital dengan Pendekatan Algoritra. Bandung: Informatika.

Prasetyo, E. (2011). Pengolahan Citra Dan aplikasinya Menggunakan Matlab. Togyakarta: ANDY.

Pusat Data Dan Informasia Kementrian Kesehatan RI. (2016, Oktober). Dipetik Juni 13, 2017, dari Pusat Data Dan Informasia Kementrian Kesehatan Republik Indonesia: hhtp://www.depkes.go.id

Putra, D. (2010). Pengolahan Citra Digital. Yogyakarta: CV Andi offset.

Syafi'i, S. I., Wahyuningrum, R. T., \& Muntasa, A. (2015). Segmentasi Obyek Pada Citra Digital menggunakan Metode Otsu Thresholding , 1-8. 